Case Report

\title{
Assessment of Body Composition in Physical Education Female Students of University of Niš
}

\author{
Ružena Popović", Aleksandra Aleksić-Veljković, Tijana Purenović-Ivanović, Aleksandra Popović \\ Faculty of Sport and Physical Education, University of Niš, Niš, Serbia \\ Email address: \\ ruzenapop@gmail.com (R. Popović), axy_gym@yahoo.com (A. Aleksić-Veljković), tijanapurenović@gmail.om (T. Purenović-Ivanović), \\ popovicaleksandra@yahoo.com (A. Popović) \\ ${ }^{*}$ Corresponding author
}

\section{To cite this article:}

Ružena Popović, Aleksandra Aleksić-Veljković, Tijana Purenović-Ivanović, Aleksandra Popović. Assessment of Body Composition in Physical Education Female Students of University of Niš. Advances in Sciences and Humanities. Vol. 6, No. 1, 2020, pp. 36-51. doi: $10.11648 /$ j.ash.20200601.15

Received: January 16, 2020; Accepted: February 12, 2020; Published: February 21, 2020

\begin{abstract}
This paper is based on the results of the cross-sectional experiment that was implemented in the school year 2015/2016, within the female students of the third year of undergraduate studies at the Faculty of Sport and Physical Education (FSPE), University of Nis. The study was for the first time realized in this school year, during the mandatory curriculum in Rhythmic gymnastics (6th semester of education, weekly classes 3+3, and 45+45, per semester). Assessment of body composition is realized along with the Pedagogical practice (as pre-exam study requirements). The sample includes $30 \mathrm{PE}$ female students, within the 3rd year of study following the Bologna Declaration. Based on the body composition assessment, the student's results are displayed in the form of histograms, for each measured variable. Comparative analysis of results was used for the consideration of the differences among examined students within the group, considering the calculated Mean values and recorded MIN and MAX results, as well as student profile model score. The results were evaluated based on the system for the assessment of body composition (OMRON BF511) and the interpretation of results for the following variables: body fat percentage, visceral fat, percentage of body muscles, body mass index (MBI), and the basal metabolic rate. The results obtained show the expected intra-group differences in body composition parameters, which are not inherited conditionally, for all of the selected body variables (except BMI). But, although the most of the values are recommended, those low percentages of high body fat (BF), and body mass index (BMI), as well as relative skeletal muscle mass values (M\%), indicate the heterogeneity of the student population, their sports orientation, and their level of physical activity.
\end{abstract}

Keywords: Body Composition, FSPE Female Students, Parallel Analysis, Case Study

\section{Introduction}

\subsection{Theoretical Background}

Body Composition*

In most population-based studies that have provided information on the relationship between physical activity and morbidity or mortality, body composition has been estimated by measuring body height and weight and calculating body mass index (weight $/$ height $^{2}$ ). The preferred method for determining the amount of body fat and lean body mass in exercise training studies has been hydrostatic or underwater weighing (NCHS, Wilmore 1989); however, this method lacks accuracy in some populations, including older persons and children (Lohman 1986). Anthropometric measurements (i.e., girths, diameters, and skinfolds) used to calculate the percentage of body fat have varying degrees of accuracy and reliability (Wilmore and Behnke 1970). [20].

Data now suggest that the distribution of body fat, especially accumulation in the abdominal area, and total body fat are significant risk factors for CVD and diabetes (Bierman and Brunzell 1992; Blumberg and Alexander 1992). Researchers have determined the magnitude of this abdominal or central obesity by calculating the waist-to-hip circumference ratio or 
by using new electronic methods that can image regional fat tissue. New technologies that measure body composition include total body electrical conductivity (Segal et al. 1985), bioelectrical impedance (Lukaski et al. 1986), magnetic resonance imaging (Lohman 1984), and dual-energy x-ray absorptiometry (DEXA) (Mazess et al. 1990). These new procedures have substantial potential to provide new information on how changes in physical activity affect body composition and fat distribution.*all citations ara by [20].

The size and body composition, which are largely predetermined by genetic inheritance, may change slightly when it comes to body size, or significantly, with proper diet (dietary regime) and exercise, when it comes to body composition. Body size means of physical size, namely volume, weight and the longitudinal parameters, and diameters, while the visual evaluation is often used to describe individuals as skinny/ectomorph, muscular/mesomorph, or obese/endomorph, as reported by Komiya, et al., 1996 [8].

A large number of studies testify that physical appearance or constitutional type is the basic framework (reference) when attempting to interpret health, the type of physical fitness, sport achievement and personality traits of human beings. Within the general framework of constitutional types, many detailed aspects that need to be examined and studied for separate interpretation. The need for selection of persons willing to study sport and physical education, including any existing method of selection and adaptation of persons to the task that requires above-average physical and sports performance.

When it questions about the entrance exam criteria for the FSPE study, own author research, in general, indicate that either of the two applied classification models (the points and score system for the evaluation of the results) does not differ significantly successful in contrary to unsuccessful candidates at the entrance examination at the University of Nis, as in Popović, R., 2015 [13].

The analysis of the original scores provides more adequate indicators, in terms of the overall assessment of achievement, of successful and unsuccessful candidates, in some parts of the entrance examination, as well as within certain variables for the assessment of a specific, classification part. The analysis of the original results (scores) provides more adequate indicators, in terms of the overall assessment of achievement, of successful and unsuccessful candidates, in some parts of the entrance examination, as well as within certain variables for the assessment of a specific, classification part.

However, the MANOVA applied indicates that there are no statistically significant differences between the successful, and rejected candidates $(\mathrm{F}=1.368, p=.352)$ in the enrollment of PE studies. The procedures used within ANOVA analysis (F-test and t-test), as well as rank analysis variance (Kruskal-Wallis test) indicate that within each specific discipline (when checking the suitability of appropriate, sports-specific task performance techniques), some tests are not discriminatory enough when it comes to the adequate selection of candidates to study physical education, according to Popović, R., 2015 [13].

It can be assumed that the somatic typology of students of the Faculty of Sport and Physical education (FSPE) is the basic procedure. This approach is necessary because almost every type of physical fitness test must be unconditionally defined or interpreted in terms of the constitutional type, according to Purenović-Ivanović, T., et al., 2013 [14]. Physical or body composition indicates the relative amount of bodily substances, such are internal organs, subcutaneous fat tissue, skeletal muscle, bone, blood, water, and other content, as listed by $W H O, 1995$, p. 5 [18].

Assessment of body composition provides a great opportunity to pre-distribution of a person's whole body size into two major structural components: body fat (BF) and lean (non-fat) body mass (LBM), i.e. relative body fat and muscles are of the extreme importance in practice, as indicated by Cvetković, Obradović, Kalajdžić, 2008 [5]. Somatotype and body composition have been examined by a large number of researchers, including (Bolonchuk, et al., 1989; Krsmanovic, et al., 1997; Srdić, Dimitrić, Obradović, 2009; Jović et al., 2010; Krick \& Raschka, 2012), taken from Purenović-Ivanović, T., et al., 2013 [14].

Although large amounts of body fat (BF) are undesirable from a health perspective, it is not possible to determine exactly the optimal body fat (BF) levels or body weight in a particular individual. Assessment of body composition, both in individuals and in populations, is important for clinical trials and for medical practices. Individuals, who are engaged in active sports activities, differ significantly in many somatic traits of those who practiced more sedentary lifestyle. Also, in all previous studies, a significant relationship was found between the physical status of PE students and their achievement in motor activities (Bale, 1978, 1979, 1980), which indicates the need to establish their physical status, according to Purenović-Ivanović, T., et al., 2013 [14].

The purpose of this pilot study was to determine the body composition in a specifically selected sample of female students, enrolled in the study of sport and physical education (FSPE), regarding creating a single report, shaped like a case study (personal profile) of the FSPE female students.

The aim of this pilot study is a comparative, intra-group, and between groups analysis of the data collected, which would give an insight into the individual status of the group, as a whole, concerning the established values, that could also indicate possible omissions in the "selection process" for Sports and Physical Education (FSPE) studies. Also, to compare the study results with previously realized research.

This pilot study is based on the trans-sectional experiment results, which was realized in the 2015/16 study year with third-year female students of Academic Studies, of Faculty of Sports and Physical Education (FSPE), University of Niš, who were included in the regular curriculum, in obligatory major Rhythmic gymnastics, (VI semester, fund of classes $3+3$ on weekly bases / $45+45$ semester bases), following the Bologna Declaration. The pilot study was for the first time completed in the before mentioned school year (May 29, 2016). Student testing and assessment of body composition were realized within the framework of the Pedagogical Practice (as a prerequisite exam compulsory). 


\subsection{Principle of Body Composition Calculation}

In most population-based studies that have provided information on the relationship between physical activity and morbidity or mortality, body composition has been estimated by measuring body height and weight and calculating body mass index (weight/height ${ }^{2}$ ).

The preferred method for determining amount of body fat and lean body mass in exercise training studies has been hydrostatic or underwater weighing (NCHS, Wilmore 1989); however, this method lacks accuracy in some populations, including older persons and children (Lohman 1986) [20].

Anthropometric measurements (i.e., girths, diameters, and skinfolds) used to calculate the percentage of body fat have varying degrees of accuracy and reliability (Wilmore and Behnke, 1970) [20]. Data now suggest that the distribution of body fat, especially accumulation in the abdominal area, and total body fat are significant risk factors for CVD and diabetes (Bierman and Brunzell, 1992; Blumberg and Alexander, 1992) [20].

Researchers have determined the magnitude of this abdominal or central obesity by calculating the waist-to-hip circumference ratio or by using new electronic methods that can image regional fat tissue. New technologies that measure body composition include total body electrical conductivity (Segal, et al. 1985), bioelectrical impedance (Lukaski, et al. 1986), magnetic resonance imaging (Lohman, 1984), and dual-energy x-ray absorptiometry (DEXA) (Mazess, et al. 1990) [20].

These new procedures have substantial potential to provide new information on how changes *in physical activity affect body composition and fat distribution. According to (U.S. Department of Health and Human Services. Physical Activity and Health: A Report of the Surgeon General. Atlanta, GA: U.S. Department of Health and Human Services, Centers for Disease Control and Prevention, National Centre for Chronic Disease Prevention and Health Promotion, 1996., pp. 36-37). *This sub-segment was cited as by [20]

\section{Methods}

\subsection{Sample}

The sample is composed of 30 respondents (FSPE female students). The basic characteristics of the sample are shown in Table 1. In the same table, for the reason of comparative analysis, are presented results of the previously conducted research, regarding the determination of body type and body composition, on the sample of respondents from the same, specific selected students population, examined by Purenović-Ivanović, T., et al., 2013 [14].

This pilot study is based on the trans-sectional experiment results, which was realized in the 2015/16 study year with the third year of Academic Studies, within female students of Faculty of Sports and Physical Education (FSPE), University of Niš. They were included in the regular curriculum, in obligatory major Rhythmic gymnastics, (VI semester, number of classes 3+3 on weekly bases / 45+45 semester bases), following the Bologna Declaration. Measuring of the current sample was conducted on May, 26th 2016, at the gym hall, of the (FSPE), University of Niš, during the term of regular classes, in the morning hours (up 10:00h to 12:15h). Student testing and assessment of body composition were realized within the framework of Pedagogical Practice (as a prerequisite exam compulsory). Testing was performed in accordance with the principles established by the Helsinki Declaration, WMA, 2002, [19].

\subsection{Measuring Instruments}

The data on the current age of years of the subjects were first entered and their body height was measured using anthropometry, according to Martin. This information was stored in the memory of the device and later used to calculate the Body composition parameters: 1) Bodyweight (kg), 2) Body mass index - BMI $\left.\left(\mathrm{kg} / \mathrm{m}^{2}\right), 3\right)$ Body fat - BF (\%), 4) Visceral fat - (level), 5) Skeletal muscle -M (\%) and 6) Basal metabolism -BM $(\mathrm{kCal})$ were evaluated by a tetra polar $\mathrm{BI}$ device, Omron BF511, Kyoto, Japan [12].

Body fat has low electric conductivity. The BF511 measures the body fat percentage by the Bioelectrical Impedance (BI) method. Muscles, blood vessels and bones are body tissues with a high water content that conducts electricity easily. Body fat is tissue that has little electric conductivity.

The BF511 sends an extremely week electrical current of $50 \mathrm{kHz}$ and less than $500 \mu \mathrm{A}$ through the body to determine the amount of fat tissue. This weak electrical current is not felt while operating the BF511. For the scale to determine body composition, it uses the electrical impedance, along with your height, weight, age and gender information to generate results based on OMRON's data of Body composition [12].

Measures the whole body to avoid the influence of fluctuations. During a day, the amount of water in the body tends to gradually shift to the lower limbs. This is why there is a tendency for the legs and ankles to swell in the evening or at the night. The ratio of water in the upper body and lower body is different in the morning and evening, and this means that the electrical impedance of the body also varies. Since the BF511 uses electrodes for both hands and feet to take measurements, it can reduce the influence of these fluctuations on measurement results.

Recommended measurement times. Understanding the normal changes in-person body fat percentage can help in preventing or reducing obesity. Being aware of the times when the body fat percentages shift with an individual own daily schedule will assist a person in obtaining an accurate trending of individual body fat. It is recommended to use this unit in the same environment and daily circumstances. See chart, Operation manual, pp. 16-17, [12]. If the measurement is taken under no regular physical conditions, the calculated body composition may differ significantly from the actual one because the water content in the body is changing.

\subsection{Statistical Procedures}

Body composition is analyzed using the Statistical Package for the Social Sciences (version IBM SPSS 10.0 SPSS Inc., Chicago, USA), and as directed by Ntoumanis, N., 2001, [11]. Descriptive statistics [the mean value (Average), the standard 
deviation (SD), Range /Interval] are summarized for all variables. Min - Max results, and personal results of the FSPE female students (presented in form of Diagrams), as well as profile model results for the case study report preparation (presented in form of Histograms).

\section{Results and Interpretation}

\subsection{Assessment of Body Composition in FSPE Students}

The data obtained are presented in tables, then in graphic form as diagrams and histograms. The results of applied descriptive statistics, of all parameters, are shown in Table 1, together with the data of the previous realized study, by Purenović-Ivanović, T., et al., 2013 [14]. All individual female student results are presented in the form of diagrams/graphs, and the calculated results are presented as well in form of histograms (for each variable examined), which provide more transparent insight into the female student profile model, who is also the co-author of this case study.

Table 1. Basic statistics parameters - FSPE female students.

\begin{tabular}{llll}
\hline Sample (N=12) & Variables & Mean \pm SD & Range \\
\hline Women (2013) & Age & $20.36 \pm 1.29$ & $19.12-22.9$ \\
Purenović-Ivanović, & BH $(\mathrm{cm})$ & $164.16 \pm 7.83$ & $155.5-179.0$ \\
T., et al. & BW $(\mathrm{kg})$ & $60.86 \pm 8.81$ & $49.2-75.8$ \\
\hline & & & 23.5 \\
\hline Sample (N=30) & Variables & Mean & 26.6 \\
Women (2016) & Age & 23.6 & Min - Max \\
Popovic, R., et al. & BH (cm) & 164.0 & $21.4-25.8$ \\
\end{tabular}

Legend: N - sample size, Mean/Average, SD/Standard deviation, Range, Min/Max, Interval/Range size, Age/years, BH-Body Height, BW-Body Weight.

The results were evaluated based on the Body Composition Determination Table (OMRON BF511) and interpretation based on presented scales for all of the determined parameters for body composition assessment: body fat percentage (BF\%), visceral fat level (VF), body mass index (MBI), skeletal muscle percentage (M\%), and resting (basal) metabolism (BM) values (Table 2).

Table 2. Body composition of FSPE female students.

\begin{tabular}{|c|c|c|c|c|}
\hline Sample (N12) & Variables & Mean \pm SD & Range & Interval \\
\hline \multirow{5}{*}{$\begin{array}{l}\text { Women (2013) } \\
\text { Purenović-Ivanović, } \\
\text { T., et al. }\end{array}$} & $\mathrm{BMI}\left(\mathrm{kg} / \mathrm{m}^{2}\right)$ & $22.59 \pm 2.41$ & $18.6-26.5$ & 7.9 \\
\hline & $\mathrm{BF}(\%)$ & $30.69 \pm 5.65$ & $24.2-41.7$ & 17.5 \\
\hline & VF (level) & $3.67 \pm 0.98$ & $2-5$ & 3 \\
\hline & Muscle (\%) & $29.58 \pm 3.6$ & $24.4-37.5$ & 13.1 \\
\hline & Basal (kCal) & - & - & - \\
\hline Sample (N30 ) & Variables & Mean & Min - Max & Interval \\
\hline \multirow{4}{*}{$\begin{array}{l}\text { Women (2016) } \\
\text { Popovic, R., et al. }\end{array}$} & $\mathrm{BF}(\%)$ & 26.5 & $16.5-35.9$ & 19.4 \\
\hline & VF (level) & 4 & $1-5$ & 4 \\
\hline & Muscle (\%) & 29 & $25.8-33.7$ & 7.9 \\
\hline & Basal (kCal) & 1150 & $1110-1487$ & 377 \\
\hline
\end{tabular}

A comparative analysis of the results was applied regarding insight at inner group differences within the examined parameters, among female students, evaluating calculated mean values and recorded Min-Max results, as well as individual student performances (shown in the diagrams), as well as result of the student profile model compared to other female students (shown in histograms), which served to produce the Report in the form of a case study.

\subsection{Diagrams and Histograms}

They are separate parts of the Omron Table, which is based on research elaborated by British authors (McCarthy, $\mathrm{H}$. D, et al., 2000), and published in International Journal of Obesity, Vol. 30, and the American (Gallagher et al., 2000), published in American Journal of Clinical Nutrition, Vol. 72, cited by OMRON, Body Composition Determination System
(Operating Instructions, pp. 16-17) [12].

The classification was conducted on 4 levels by Omron Healthcare. This paper presents only particular data of this table, regarding female adults, aged up 18 to 39 years (by parameters).

Based on the conducted testing, the individual female student's results are presented in the Diagrams/Figures form (up 1 to 8). A comparative analysis of the results was used for the consideration of possible significant differences among tested FSFV female students, within a group, looking at the calculated mean value/Average, and recorded Min, and Max results, as well as individual achievement of profile model in the study group (shown in form of Histograms/Figures (up 9 to 16).

\subsubsection{Age of FSPE Female Students (Age/Month)}

In Figure 1 (Age/Month) are provided data on the 
chronological age of female students, noticed in months. According to the above distribution of results, it is evident that female students, concerning age, are distributed within the same equidistant class, i.e., there is a little mutual difference, witch points out that they belong to the correspondent annual, except one, which belongs to senior class, with Max-score of (310) months (outliner). This female student has, due to objective reasons, more time repeated study year, so she has delayed with the completion of certain exam term responsibilities of $\mathrm{RG}$, in which time was conducted testing of students, to regulate educational practice activities. All other data, except Min values, are within the zone below the average values $(93.33 \%)$.

\subsubsection{Body High (BH) of FSPE Female Students}

In Figure 1 (BH - Body High) are included data of the student's Body High, measured as precise as $0.5 \mathrm{~cm}$. According to the displayed distribution of results (as Diagram), it is evident that respondents were divided into two equidistant classes, which indicates on small mutual differences in terms of sample homogeneity, except in the case of one female student, who was measured with Max-result $(182.5 \mathrm{~cm})$ of the $\mathrm{BH}$, located in the third equidistant class as (outliner). In total sample of the female students $(30 \%)$ were in the below-average zone of $\mathrm{BH}$ values, and (70\%) PE students were above-average within the group.

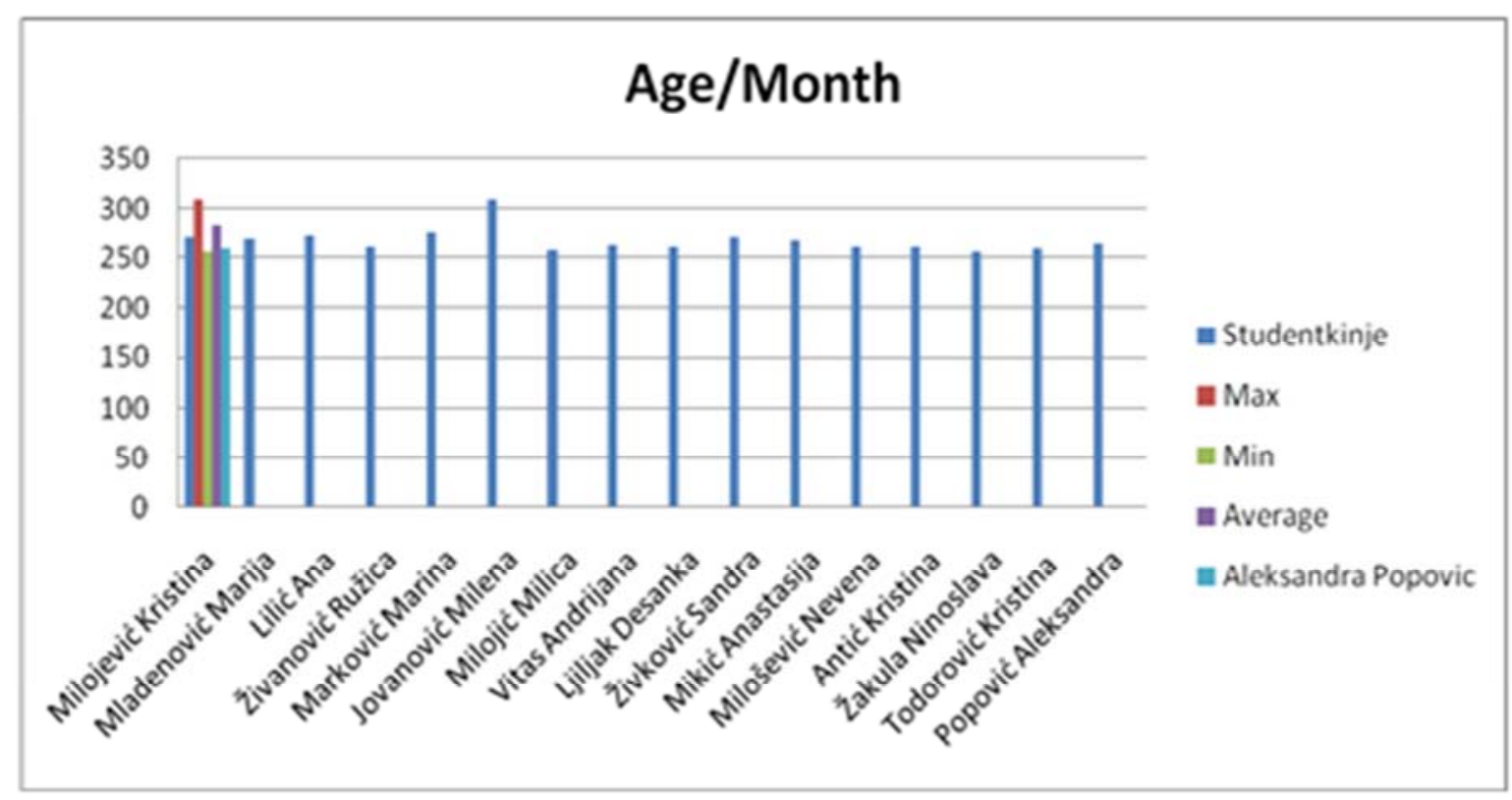

Legend: Studentkinje-FSPE students, Max-310, Min-257, Average-280, Profile model A. P. (260).

Figure 1. Age/Month.

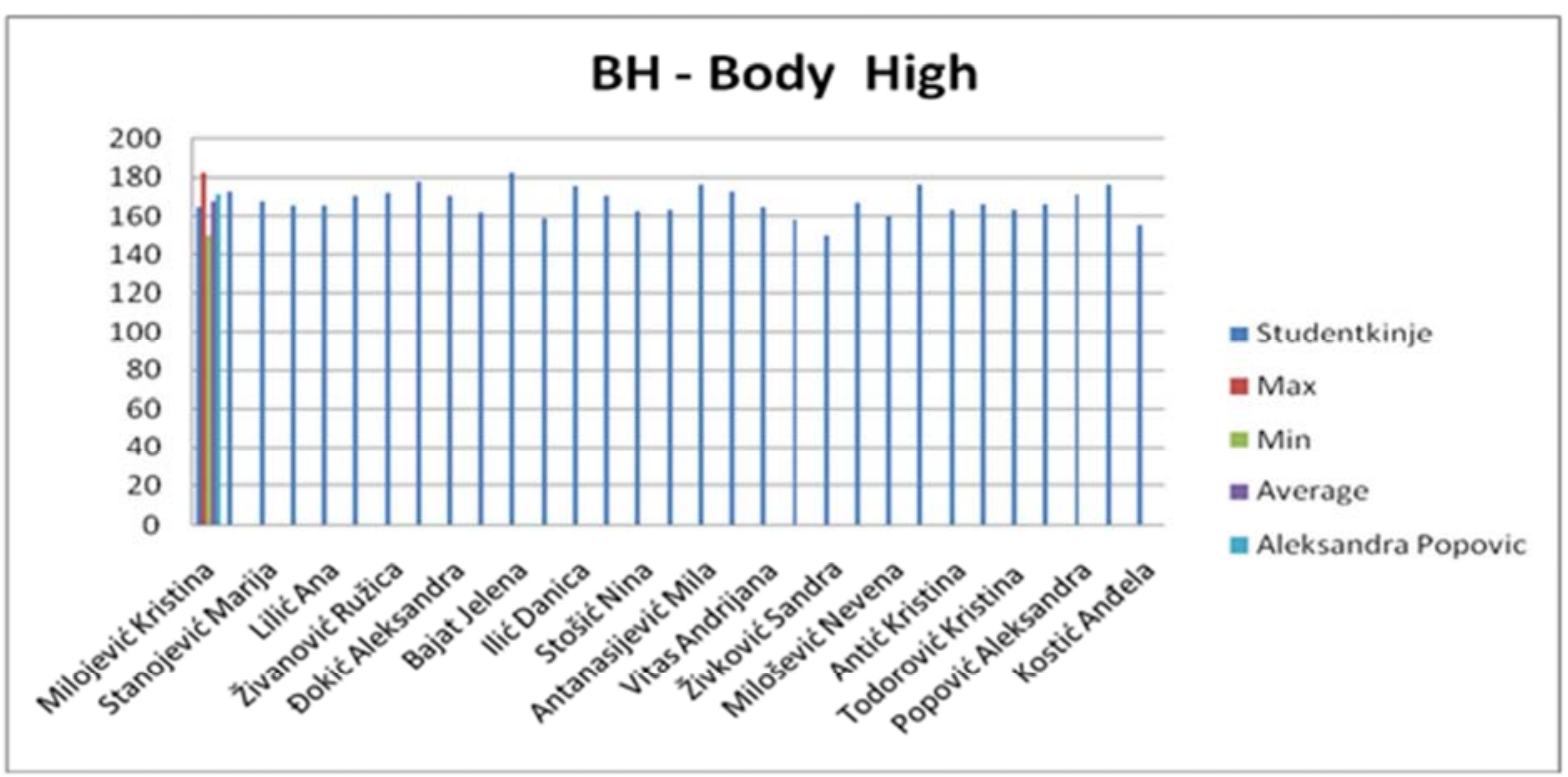

Legend: Studentkinje-FSPE students, Max $(182.5 \mathrm{~cm})$, Min $(150 \mathrm{~cm})$, Average $(164 \mathrm{~cm})$, Profile model A. P. (171.9 cm).

Figure 2. Body High (BH). 


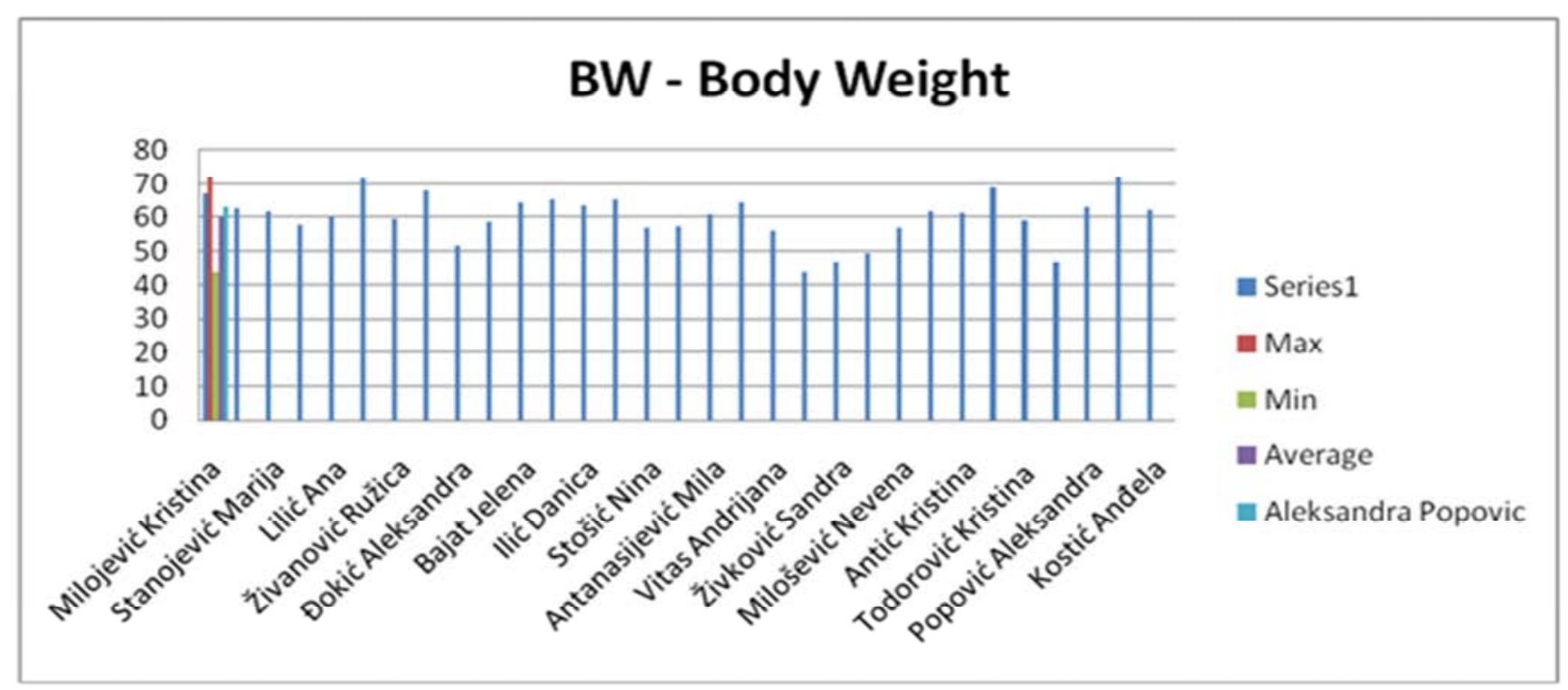

Legend: Series1 - FSPE students, Max (72.2 kg), Min (43.7 kg), Average (60 kg), Profile model A. P. (63 kg).

Figure 3. Body Weight (BW).

\subsubsection{Diagram - Body Weight (BW) of FSPE Students}

In Figure 3 (BW - Body Weight) are listed the data on measured body weight of FSPE female students expressed as precise as $(0.5 \mathrm{~kg})$. According to this results distribution, it is evident that the FSPE female students are distributed in three equidistant classes, which indicates significant, numeric, intergroup differences. However, half of the students make up a homogenous group (50\%), and within them are registered below-average values of $\mathrm{BW}$, and the remaining results are the above average $(50 \%)$, which also includes the Max-result of BW $(72.2 \mathrm{~kg})$, placed in the third equidistant class (outliner).

\subsubsection{Body Mass Index (BMI) of FSPE Female Students}

Body Mass Index uses the following simple formula to indicate the ratio between weight and height of a person:

$$
\text { BMI [Weight }(\mathrm{kg}) / \text { Height }\left(\mathrm{m} / \mathrm{m}^{2}\right) \text { ] }
$$

The Omron BF511 uses the height information, stored into a personal profile number or when entering information in the Guest Mode to calculate individual BMI classification. If the fat level revealed by BMI is higher than the international standards, there is an increased likelihood of common diseases. However, not all types of fat can be revealed by BMI.

Table 3. Body mass index (BMI) classification.

\begin{tabular}{lll}
\hline Body Mass Index & BMI (WHO Determinants) & BMI levels \\
\hline \multirow{3}{*}{ less than 18.5} & & $7.0-10.7$ \\
& - (low obesity) & $10.8-14.5$ \\
\multirow{2}{*}{18.5 or more, and less than 25} & & $14.6-18.4$ \\
& 0 (normal) & $18.5-20.5$ \\
& & $20.6-22.7$ \\
25 or more, and less than 30 & & $22.8-24.9$ \\
& + & $25.0-26.5$ \\
& & $26.6-28.2$ \\
30 or more & & $28.3-29.9$ \\
& ++ (obesity) & $30.0-34.9$ \\
\hline
\end{tabular}

Source: World Health Organization (WHO).

In Figure 4 Body Mass Index (BMI), is listed as the data on the ratio of the body high $(\mathrm{BH})$ and body mass $(\mathrm{BM})$ of subjects, calculated as precise as $(0.5 \mathrm{~cm}$, and $0.1 \mathrm{~kg})$. Evaluation of results is by OMRON scale for adult female persons, aged up 18-39 years (see the classification distributed in four levels). According to the above-presented distribution of results, it is evident that the FSPE female students are most distributed in two equidistant class $(40 \%)$, one of which have below average result, while at the $(60 \%)$ are registered above average results, where it belongs the Max value of BMI (25.7), which exceeds the zone of (0) Normal obesity and there is in the zone of $(+)$ pre-obesity (outliner). 


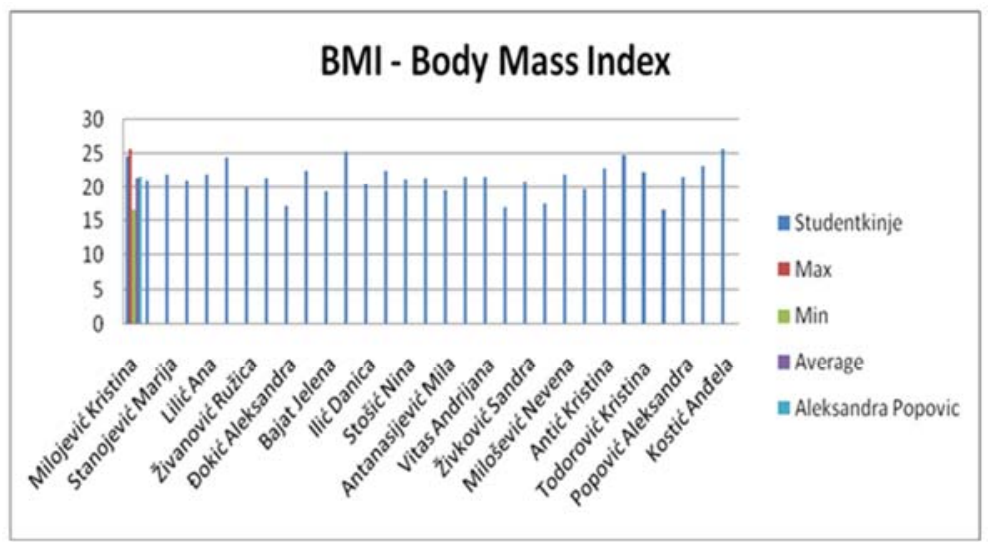

Legend: Studentkinje -PE students, Max: 25.7 (+) Pre-Obesity, Min: 17.7 (-) Low Obesity, Average: 21.5 (0) Normal Obesity, Profile model A. P. 21.5 (0).

Figure 4. Body Mass Index (BMI).

\subsubsection{Body Fat Percentage (BF\%) of FSPE Students}

Body Fat Percentage refers to the amount of body fat mass in regards to the total body weight expressed as a percentage. The device uses BI method to estimate your:

Body fat percentage (\%) \{body fat mass (kg)/Bodyweight) $\}$ $\times 100$

Depending on where fat is distributed in the body, it is classified as visceral fat or subcutaneous fat (below the skin). Subcutaneous fat not only accumulates around the stomach but also around the upper arms, hips and thighs, and can distort the body's proportions. Although not directly linked to increased risk of disease, it is thought to increase pressure or the heart and other complications. Subcutaneous fat is not displayed in this unit, but is included in the body fat percentage.

In Figure 5 are reported data on the relative body fat $(\mathrm{BF} \%)$ of the FSPE female students, expressed as a percentage with an accuracy of $(0.1 \%)$, according to the OMRON scale for young female adults, up 18 to 39 years of age. According to the presented distribution of results, it is evident that female students are distributed in more equidistant classes, which indicates significant differences, regarding the homogeneity of the group. According to the table below, Max-value (35.9\%) corresponded to the level of + (high) percentage of body fat and it is only located in the boundary equidistant class (outliner), as well as the result of student profile model, A. P. $(33.3 \%)$, located within the + (high) level of relative $\mathrm{BF} \%$ (6.67\%). Min- result (16.5\%) represents - (low) percentage of body fat, which posses in total $(13.3 \%)$ of subjects, while the average value of $\mathrm{BF} \%(26.5 \%)$ corresponded to 0 (normal) level and it is recorded in $(80 \%)$ of FSPE female students.

Table 4. Body fat percentage (B-F \%).

\begin{tabular}{lllll}
\hline Age & - (low) & 0 (normal) & + (high) & ++ (very high) \\
\hline $18-39$ & $<21.0 \%$ & $21.0-32.9 \%$ & $33.0-38.9 \%$ & $>39.0 \%$ \\
\hline
\end{tabular}

Source: Omron Healthcare.

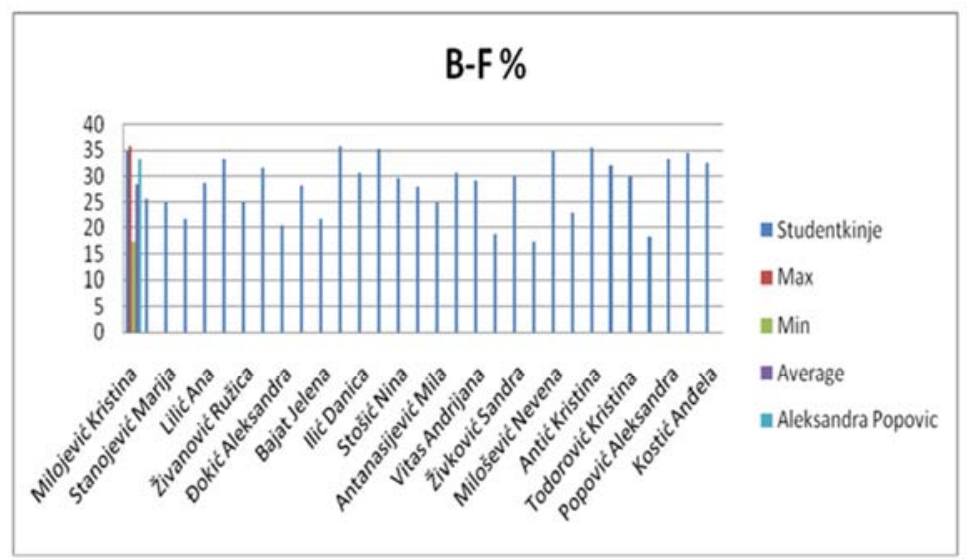

Legend: Studentkinje-FSPE students, Max (35.9\%) + (high), Min (16.5\%) - (low), Average (26.5\%) 0 (normal), Profile model A. P. (33.3\%) + (high).

Figure 5. Body fat percentage (B-F\%).

\subsubsection{Visceral Fat (VF) in FSPE Female Students}

Visceral FatFat Surrounding Internal Organs - Too much visceral fat is thought to be closely linked to increased levels of fat in the bloodstream, which can lead to common diseases such as hyperlipidemia and diabetes, which impairs the ability of insulin to transfer energy from the bloodstream and using it 
in cells.

To prevent or improve conditions of common diseases, it is important to try and reduce visceral fat levels to an acceptable level. People with high visceral fat levels tend to have large stomachs. However, this is not always the case and high visceral fat levels can lead to metabolically obese. Metabolically obese (visceral obesity with normal weight) represents fat levels that are higher than average, even if a person's weight is at or below the standard for their height.

Table 5. Visceral Fat levels.

\begin{tabular}{ll}
\hline Visceral fat level & Classification level \\
\hline $1-9$ & 0 (normal) \\
$10-14$ & + (high) \\
$15-30$ & ++ (very high) \\
\hline
\end{tabular}

Source: Omron Healthcare.
In Figure 6 (VF) are informative data on visceral fat of the FSPE female students, presented in levels, with the whole number (as proposed on the OMRON scale of classification for adults female persons). According to the above-presented distribution of the results, it is evident that the results of the subjects have been classified in five equidistant classes, which indicated on the higher inhomogeneity of group, though, all the results Min (1), Max (5), average (4), point out to 0 (normal) level of VF (1-9), as well as the result of profile model student A. P. (3). This should take into account that the classification was carried out in the general population of women, those which are not from this area, while the FSPE students are considered as specific selection samples (drawn of the general population) after passing the entrance exam.

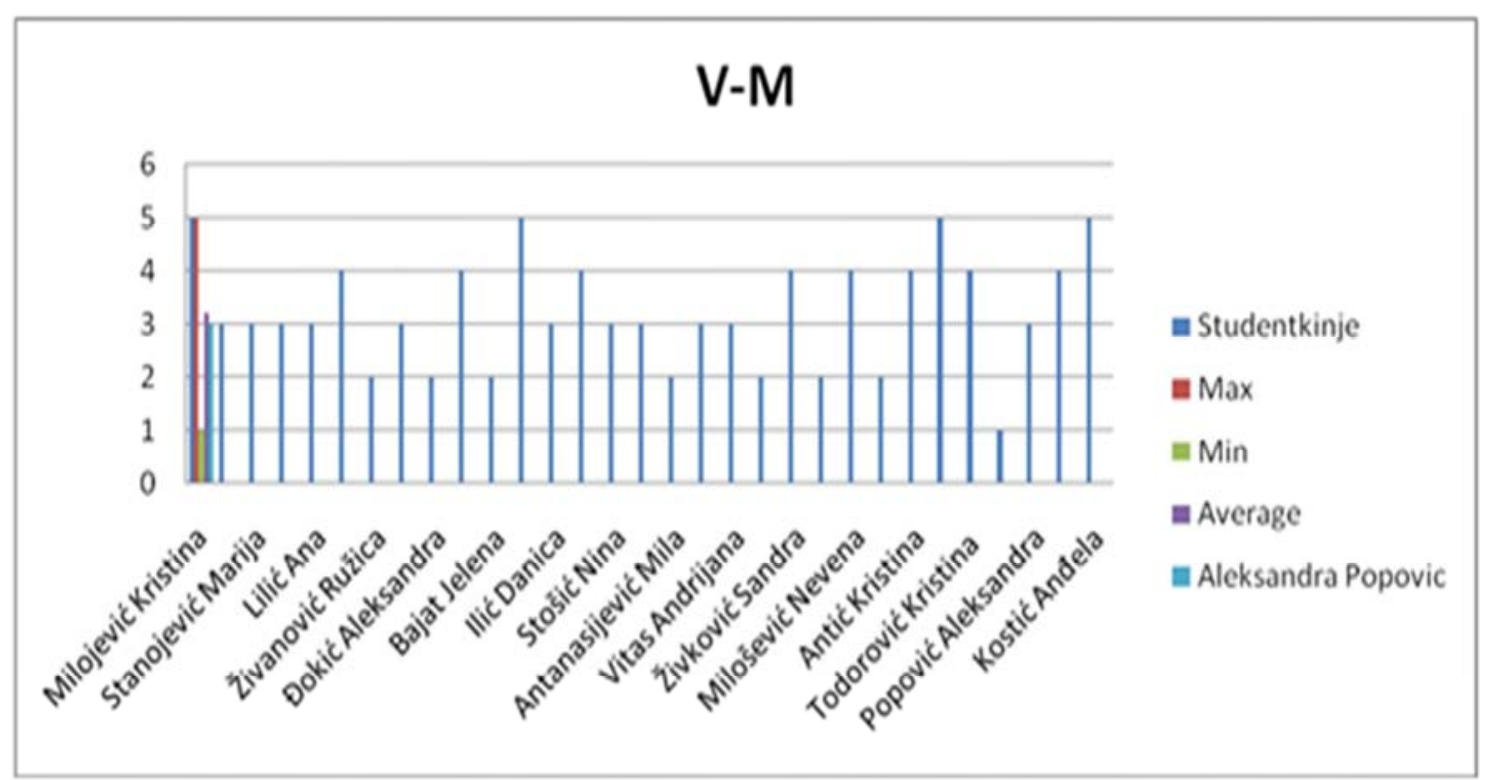

Legend: Studentkinje-FSPE students, Max (5), Min (1), Average (4), Profile model A. P. (3) Level up 1 to 9 (normal).

Figure 6. Visceral fat (VM).

\subsubsection{Percentage of Skeletal Muscles (SM\%) in FSPE Female Students}

What is Skeletal Muscle? Muscles are divided into two types: muscle in internal organs (such as the heart), and skeletal muscle (attached to bones) that is used to move the body. Skeletal muscle can be increased through exercise and other activities. Increasing the ratio of skeletal muscle means that body can burn energy more easily, which means that it is less likely to turn to fat, and makes it easier to lead an energetic lifestyle.

In Figure 7 is referred the data on the relative presence of the skeletal muscles (SM\%), in PE female students, expressed with (\%), as specified in the OMRON scale for young people and adults female persons, aged up 18 to 39 years of age.
Table 6. Skeletal Muscle Percentage.

\begin{tabular}{llllll}
\hline Gender & Years & - (low) & 0 (normal) & + (high) & $\begin{array}{l}++(\text { very } \\
\text { high) }\end{array}$ \\
\hline Female & $18-39$ & $<24.3 \%$ & $24.3-30.3 \%$ & $30.4-35.3 \%$ & $>35.4 \%$ \\
\hline
\end{tabular}

Source: Omron Healthcare.

According to the presented distribution of results, it is evident that the PE students are distributed within the two equidistant classes, which point out the higher homogeneity of the group, concerning this parameter of the Body composition. Max $(33.7 \%)$ is placed in zone + (high values) as well as the 26.7 percentage of the PE students, while the other results: Min (28.5\%), average (29\%) and of profile model (26.8\%), in total 73.3 percentage are placed in the 0 (normal) zone values. 


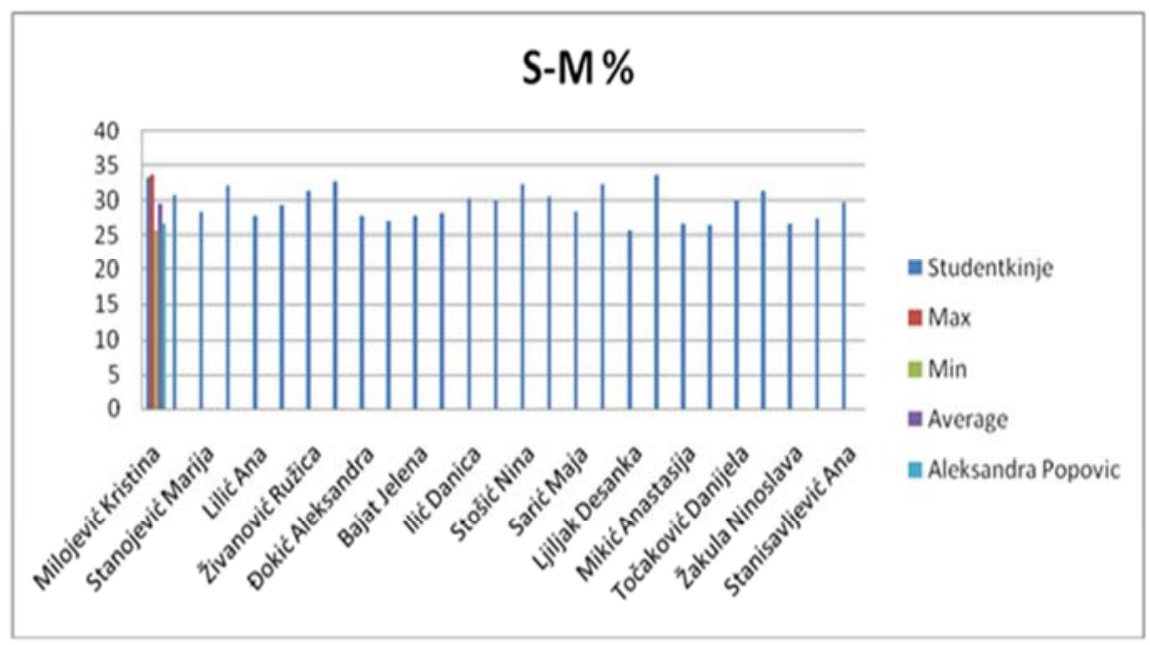

Legend: Studentkinje-FSPE students, Max (33.7\%) + (high), Min (25.8\%) 0 (normal), Average (29\%), 0 (normal), Profile model A. P. (26.8\%) 0 (normal).

Figure 7. Skeletal Muscle Percentage (S-M\%).

\subsubsection{Basal Metabolism (BM) in FSPE Female Students}

What is Resting Metabolism?

Regardless of the person's activity level, a minimum level of caloric intake is required to sustain the body's everyday functions. Known as the resting metabolism, this indicates how many calories people need to ingest to provide enough energy to their body to function.

In Figure $8(\mathrm{BM})$ is listed data on basal metabolism of a female students, expressed by the consumption of $\mathrm{kCal}$ during the rest period, on the OMRON scale for young adult female persons. According to the presented distribution of the results, it is evident that the female students are allocated into three equidistant classes, which indicates the existence of certain intra-group differences within respondents. In zone of below-average values $(1150) \mathrm{kCal}$ is distributed $(40 \%)$ of the examinees', while those of $(60 \%)$ are in zone of above-average values.

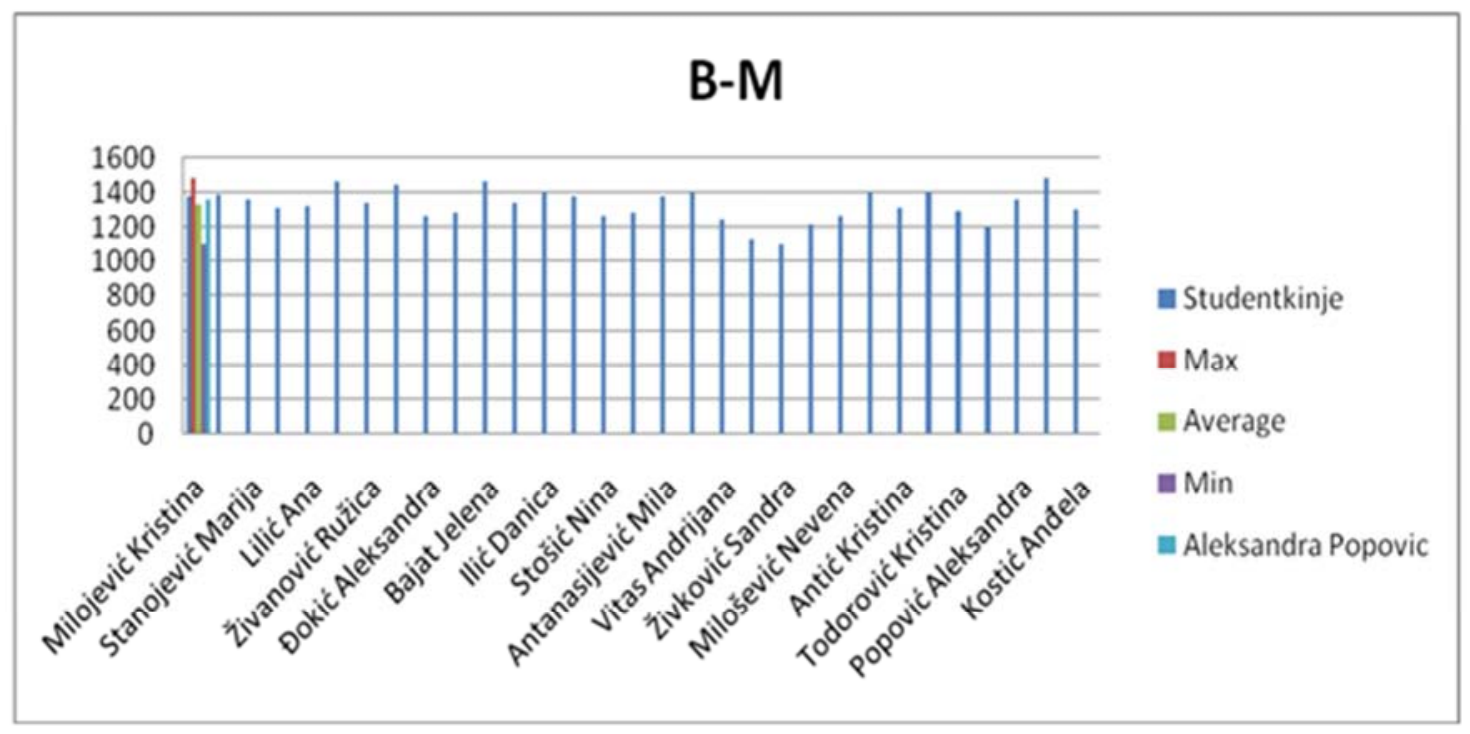

Legend: Studentkinje-FSPE students, Max (1487) kCal, Min (1110) kCal, Average (1150) kCal, Profile model, P. A. (1367 kCal).

Figure 8. Basal metabolism (BM).

\subsection{Case study Report - Interpretation of the Results for the Assessment of the Body Composition in FSPE Female Students and Profile Model}

On the following Figures (9 - 16) are presented recalculated mean values (Average), compared with registered Min - Max data, regarding the years of age of the respondents, the results of anthropometric parameters measurement (BH, and $\mathrm{BW})$, as well as measures for the assessment of body composition in the sample $(\mathrm{N} 30)$, of female students and the results of a profile model (Aleksandra Popović). As the co-author of this study, she has contributed to the Case Study Report, based on the comparative analyses of hers results, to the recorded or re-calculated values of the FSPE female students group. 


\subsubsection{Chronological Age of FSPE Female Students}

In Figure 9 (Age/Month) are presented the chronological years of age values in FSPE students, expressed in months than converted to years of age, shown in decimal numbers. Min value (257) was recorded with student Kristina Todorović, who was 21.4 years old on the day of testing. The Average age of the FSPE female students (283.5) was 23.6 years, Max-value (310) was determined with Milena Jovanović, who was 25.8 years old, while in a profile model, Aleksandra Popović was recorded value (260), of 21.7 years old, which is in the zone of the lowest values. All results, except the Max, which has to be considered as exception (outliner), are distributed within the same equidistant class, in the zone of generation values. It was estimated the great homogeneity of the group in terms of chronological age.

\subsubsection{Body High (BH) of the FSPE Female Students}

In Figure 10 are presented the measured body high $(\mathrm{BH})$ values in FSPE female students. Min-value $(150 \mathrm{~cm})$ was recorded with student Sandra Živković. The calculated mean value/Average $(167.85 \mathrm{~cm})$ of BH in FSPE female students, Max-value $(182.5 \mathrm{~cm})$ was observed in Jelena Bajat, while at the profile model, $A$. $P$. is measured BH $(171.9 \mathrm{~cm})$, which falls within the above-average zone, for this sample of FSPE female students considered to be specifically selected concerning the general adult female population in our country.

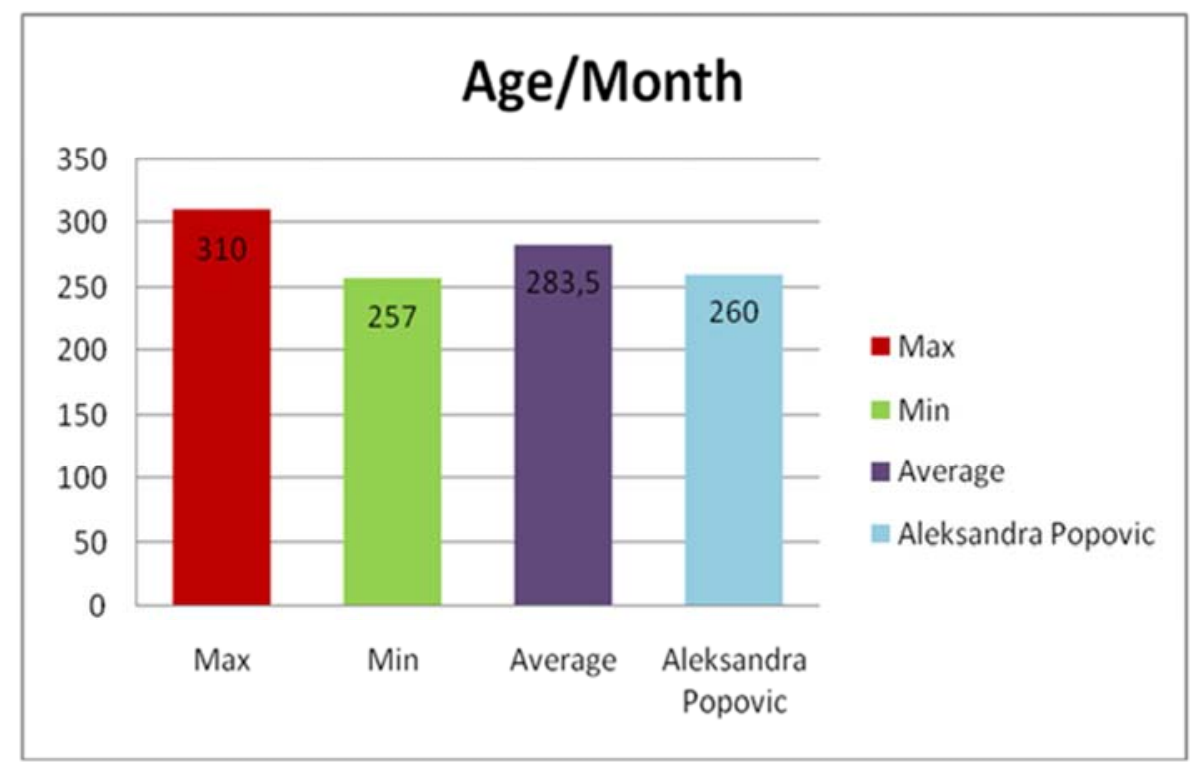

Figure 9. Chronological age (Age/Month).

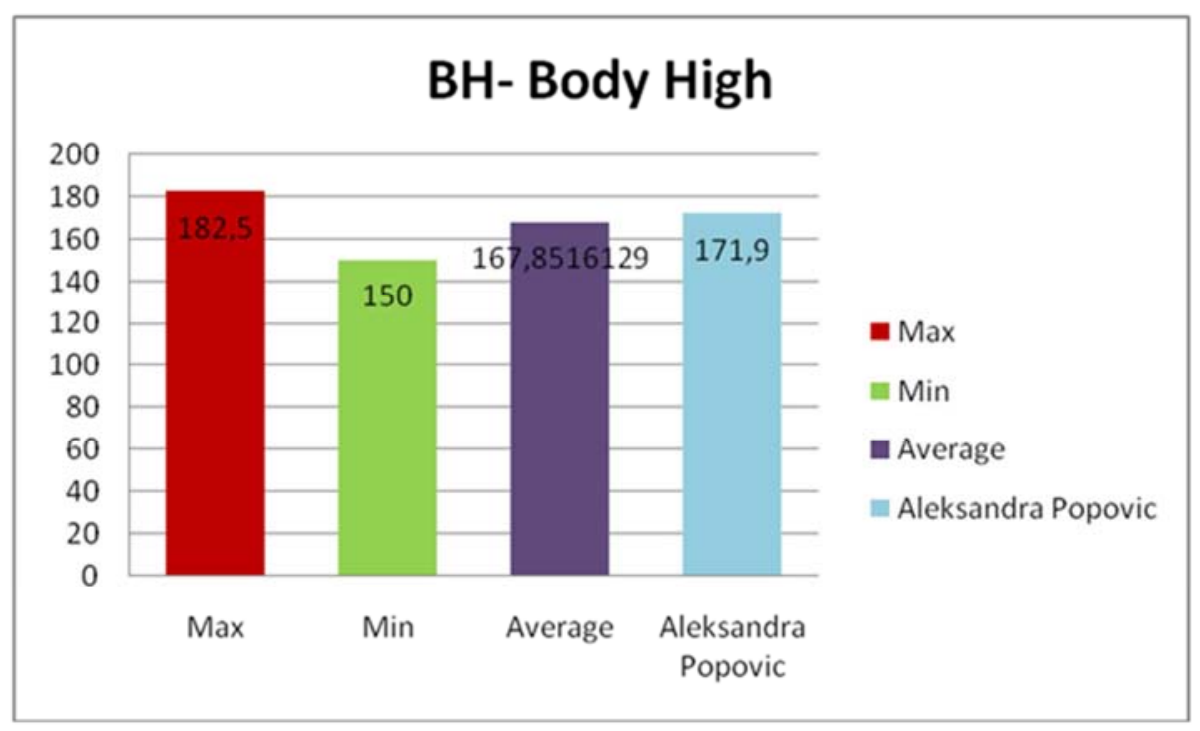

Figure 10. Body high (BH).

\subsubsection{Body Weight (BW) of the FSPE Female Students}

In Figure 11 are presented the comparative values of measured body weight (BW) of the FSPE female students on the day of testing (May 28, 2016). Min-value (43.7 kg) was recorded with Desanka Ljiljak.

The calculated mean value/ Average of BW in FSPE female 
students is $(60.25 \mathrm{~kg})$, Max-value of the body weight $(72.2 \mathrm{~kg})$ was recorded at Dragana Ranđelović, while at the profile model, A. P. measured body weight (BW) was $(63 \mathrm{~kg})$, which belong to the zone of the above-average values of the specifically defined sample of the FSPE female students.

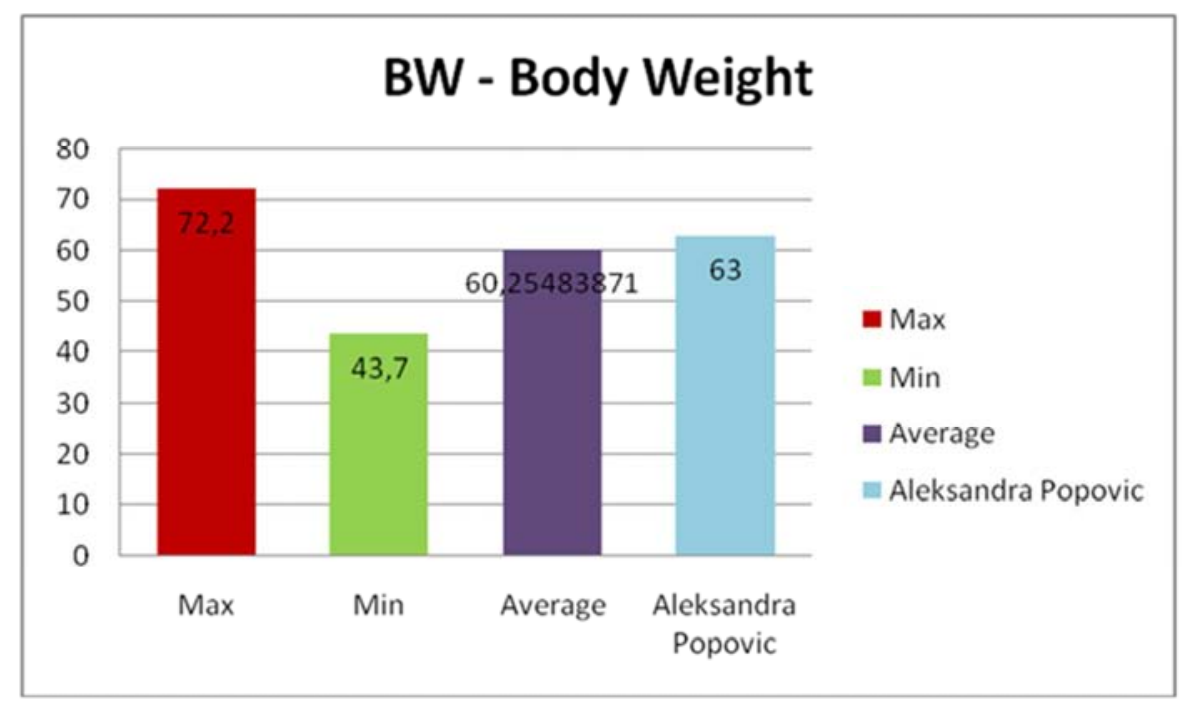

Figure 11. Body Weight (BW).

\subsubsection{Body Mass Index (BMI) of FSPE Female Students}

In Figure 12 are presented the values of Body Mass Index (BMI), in FSPE female students, on the day of testing (28.05.2016). Min-value (16.7) was recorded with student Ana Stanisavljević. Calculated mean value/Average is (21.4) of the amounts, which is within the normal values, for this age of the FSPE female students, Max-value (25.7) was recorded in Anđela Kostić, and this result indicates on + (mild obesity), while in profile model $A$. P. was recorded BMI (21.5) units, which falls in the zone of average values within the group, and according to the OMRON scale for this age of female students in the zone of 0 (normal) values (18-25).

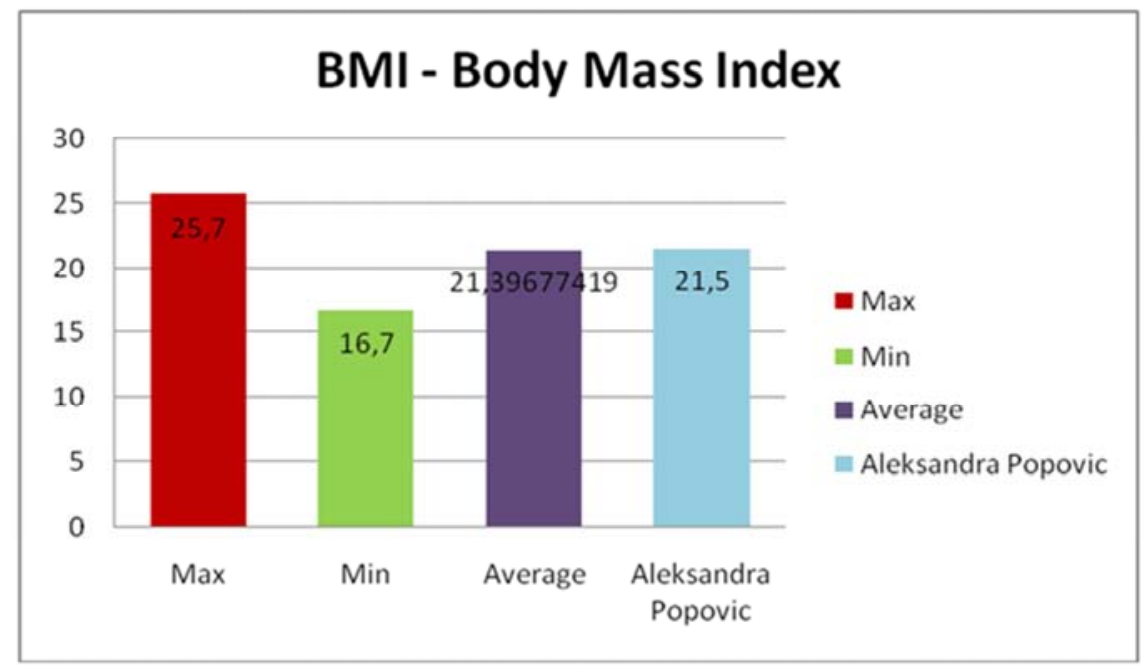

Figure 12. Body Mass Index (BMI).

\subsubsection{Body Fat (BF\%) in FSPE Female Students}

In Figure 13 are presented the relative values of body fat percentage $(\mathrm{BF} \%)$, in FSPE female students, on the day of testing.

Min-value (17.3\%) was recorded with student Anastasija Mikic. The mean value/Average of the BF\% (28.45\%), falls within the normal values for this age of FSPE female students, as well as by OMRON scale for young female adults
(21\%-32.9\%).

Max-value of $\mathrm{BF} \%(35.9 \%)$ was recorded with Milena Jovanović, while with profile model A. P. was recorded BF\% $(33.3 \%)$, which belong to the zone of the above-average values of the group, and according to the OMRON scale for this age group of women in the zone of + high values (33.0 - 38.9\%).

The mean value (Average) of the BF\% (28.45\%), falls within the normal values for this age of FSPE female students, as well as by OMRON scale for young female adults (21\%-32.9\%). 
Max-value of $\mathrm{BF} \%(35.9 \%)$ was recorded with Milena Jovanović, while with profile model $A$. P. was recorded $\mathrm{BF} \%$ (33.3\%), which belong to the zone of the above-average values of the group, and according to the OMRON scale for this age group of women in the zone of + high values (33.0 - 38.9\%).

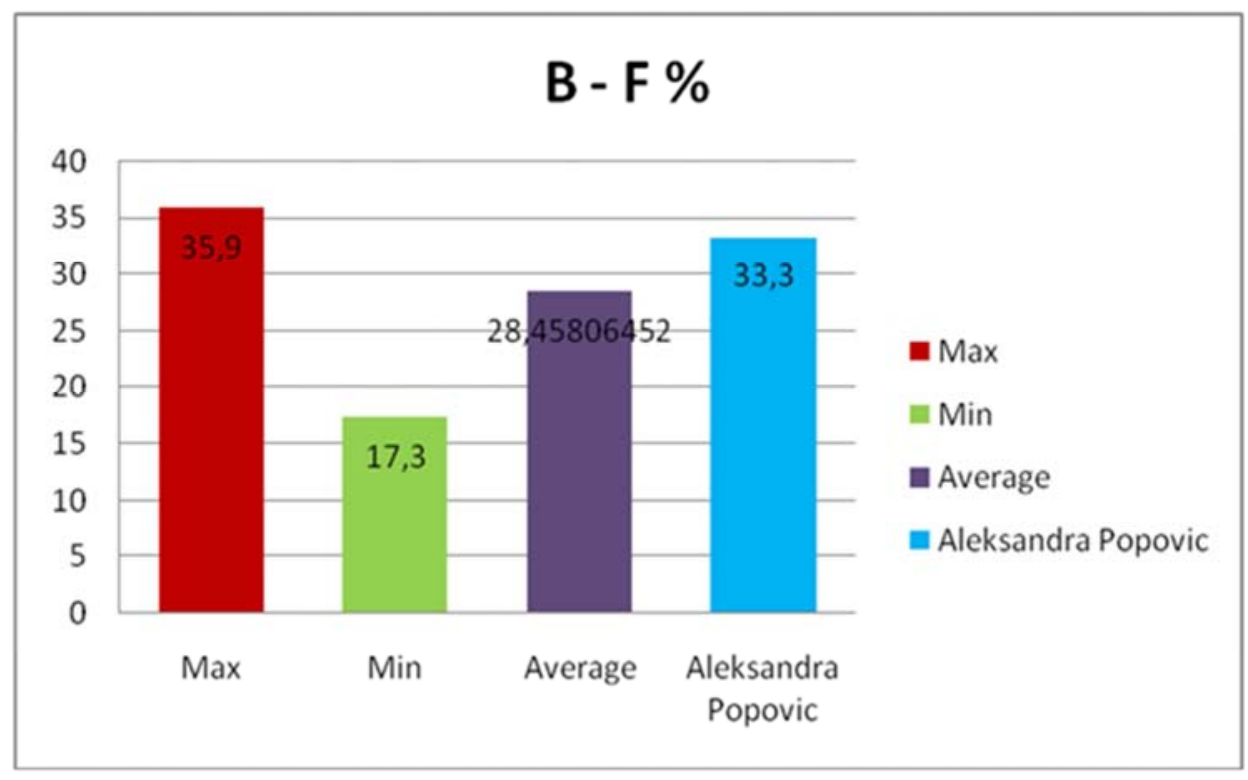

Figure 13. Body fat (B-F\%).

\subsubsection{Visceral Fat (VF) in FSPE Female Students}

In Figure 14 are presented the measured values of visceral fat (VF) in FSPE students on the day of testing. Min-value (1) was recorded with student Anđela Kostić. The Average value of the visceral fat was (3.22), and falls within the normal values for this age of FSPE female students. Max-value of the visceral fat (5) was recorded at Ana Stanisavljević, while at the profile model, Aleksandra Popović, was recorded the value of visceral fat of the (3) units, which falls within the below average zone in FSPE female students group, and according to the OMRON scale for this age of adult persons, to the zone of normal values (1-9).

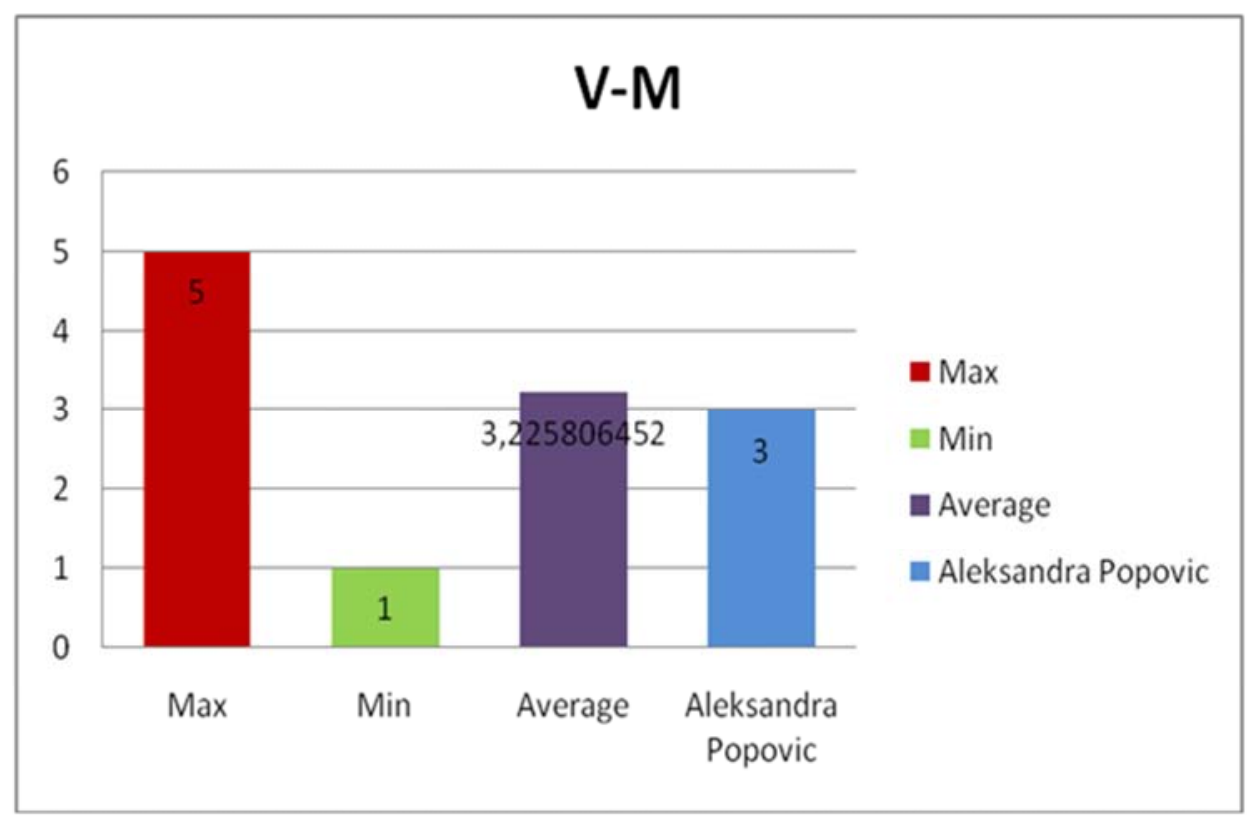

Figure 14. Visceral Fat (VM).

\subsubsection{Skeletal Muscle Percentage (SM\%) in FSPE Female Students}

In Figure 15 are presented the percentages of skeletal muscle (SM\%) in FSPE female students, measured on the day of testing. Min value of $(25.8 \%)$ was recorded with student Nevena Milošević. Calculated mean value/Average (29.63\%) 
percentage of the skeletal muscles, within FSPE female students, falls into the zone of normal values for this group, as well as according to the OMRON scale for adult female persons. Max value (33.7\%) of skeletal muscle percentage was recorded in Danijela Točaković, which belongs to the zone of + high values, according to the OMRON scale (30.4-
35.4), while in the profil model A. P. percentage of skeletal muscles $(26.8 \%)$ were recorded, which falls into the zone of the below-average values within the group, but according to the OMRON scale for this age of adult female person (24.3 30.3 ) it belongs to the normal zone.

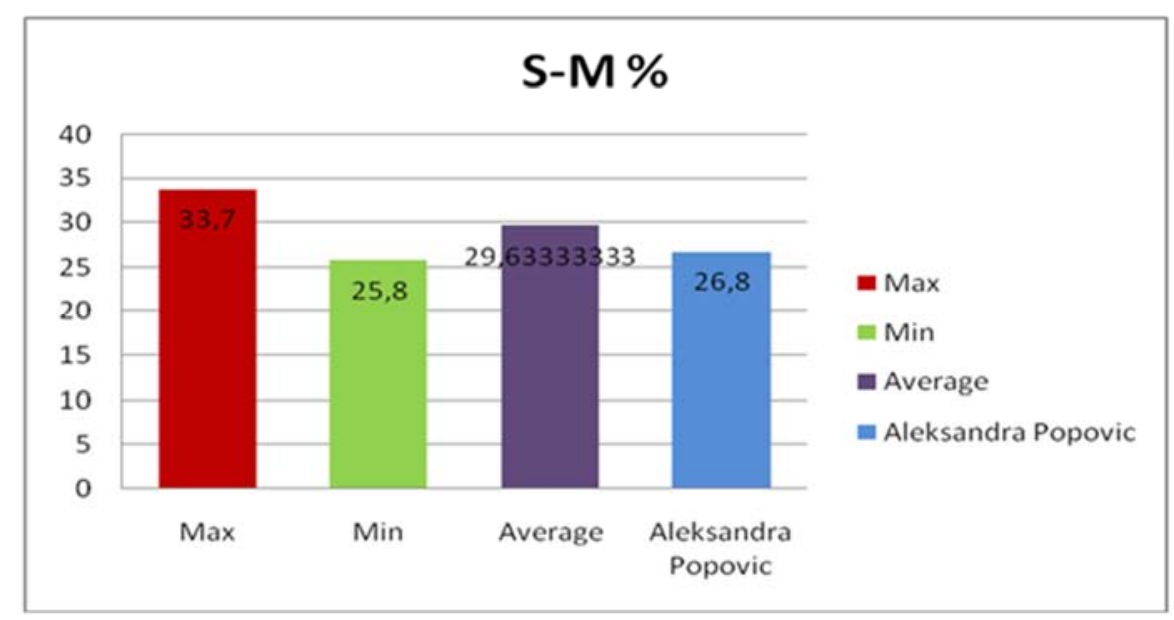

Figure 15. Skeletal muscle percentage of (S-M\%).

\subsubsection{Basal Metabolism (BM) of FSPE Female Students}

In Figure 16 are presented the basal metabolism (BM) values within the FSPE students on the day of testing. Min-value (1110 kCal) was recorded at Sandra Živković. The calculated Average of basal metabolism is $(1332.13 \mathrm{kCal})$, which is within the zone of the normal range for this sample of FSPE female students. Max-value of BM (1487 kCal) was recorded with Dragana Ranđelović, while in the profile model A. P. was recorded the value of BM (1367 kCal) (normal).

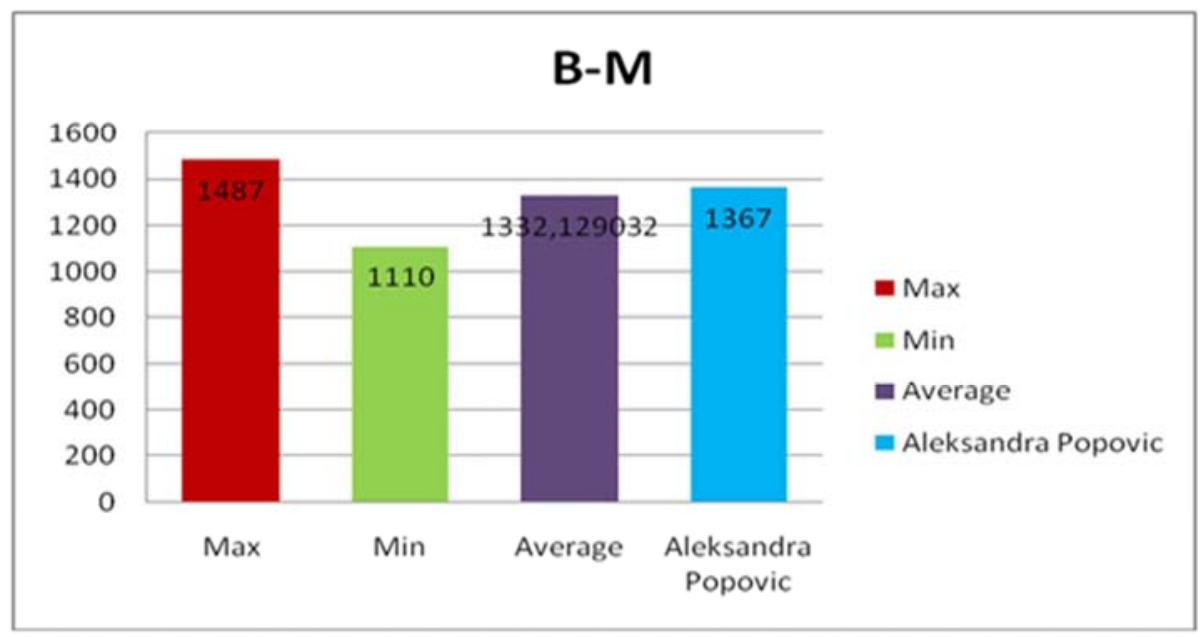

Figure 16. Basal Metabolism (B-M).

\section{Discussion}

The measurements of individual segments of anthropological status in athletes, as well as the determination of the constitution, somatotype and the body composition of the high-level sport are very important in the process of the primary selection, as well as directed selection to the particular sport, or discipline, for monitoring and evaluating the training process, for objective assessment of general physical development, control of the athlete's nutritional status and monitoring of the athlete's recovery in the rehabilitation process. Besides talent, adequate body composition is a prerequisite for success in the sport as well as in the study of Physical Education (PE).

This study is a very complex, since, in addition to meeting the requirements for entry of all faculties, at the entrance exam for the PE faculty have to be checked physical abilities, as well as the state of health in which is carried out as well the assessment of certain parameters of the body status.

Body composition is largely genetically predisposed, but 
within defined limits, and it is also subject to the impact of the environment (the degree of sensitivity to the external environment is also hereditary preconditioned), as is noticed by Purenović-Ivanović, T., et al., 2013 [14].

Female FSPE students of the third year of study (N30), regarding age, are very homogeneous group, so they can be considered as members of the correspondent year when enrolling in the study of Physical Education. Although, the average age of the respondents (23.6) is calculated, with the interval of ( 4.4 years) does not provide such a picture, because of the presence of one female student, of a senior age, who is except (outliner).

When we compare this data with female students in the first year of FSPE study (N12), we expect, on average (20.4) younger female students, with an interval of (3.8 years), indicating their greater homogeneity in terms of generational affiliation.

In FSPE female students of the third year of study, all measured values are distributed within the same equidistant class, with one exception of Max's result (outlier). And the calculated average is $(164 \mathrm{~cm})$, with a large interval of $(32.5$ $\mathrm{cm})$.

Studied anthropometric parameters, with both samples of FSPE female students, clearly indicating the existence of a certain, intra-group differences in body high ( $\mathrm{BH})$, and body weight $(\mathrm{BW})$, as expected, although there is present more group homogeneity according to $\mathrm{BH}$, in the sample of female students in the first year of study $(\mathrm{N}=12)$, where the average is $(164.1 \mathrm{~cm})$ with established interval of $(23.5 \mathrm{~cm})$ is calculated.

Female FSPE students $(\mathrm{N}=30)$ as to body weight $(\mathrm{BW})$, were distributed into three equidistant classes, indicating significant, intra-group differences. The calculated average BW $(60 \mathrm{~kg})$, with an interval of $(32.1 \mathrm{~kg})$, indicates a great heterogeneity of the sample, and this situation is similar for the group of first-year students $(\mathrm{N}=12)$. It was calculated an average value of BW $(60.8 \mathrm{~kg})$ with an interval of $(26.6 \mathrm{~kg})$ which, also, indicates a high heterogeneity of the sample.

According to Martin's referent body height $(\mathrm{BH})$ values, distributed into seven categories, $50 \%$ of FSPE female students are tall, $33.33 \%$ are of average body height, $8.3 \%$ are above average, and $8.3 \%$ are very tall, according to Simić, Vasić, Jakonić, 2010 [15].

Body mass index (BMI) in both FSPE female student samples indicates a fairly uniform of measured values. In the third year of study students $(\mathrm{N}=30)$, the calculated average is (21.5) units, with an interval of (8) units, while in the younger group of respondents a slightly higher average value (22.6) was calculated, with an interval of (7.9) units. Both average results were classified into the normal range (18-25), for this age scale of the adult female respondents.

According to the benchmarks (WHO, 2000, 9), more than $50 \%$ of the measured subjects, both sexes, (F-83.33\%, M-62.5\%) have normal BMI values and the rest are overweight (F-16.67\%, M-37.5\%), according to Purenović-Ivanović, T., et al., 2013 [14].

The comparative analysis of the situation regarding the relative body fat $(\mathrm{BF} \%)$ is slightly different. The calculated relative average value (26.5\%) in the older FSPE female student group (N30), indicates on lower relative body fat values, but also large non-uniformity of the group, with an interval of (19.4), compared to the younger group $(\mathrm{N}=12)$, which on average $(30.7 \%)$ have a higher percentage of relative body fat, but also a higher group homogeneity, with an interval of (17.5).

According to the original table (Omron, 2002, p. 11), the situation regarding the relative body fat $(\mathrm{BF} \%)$ is as follows: in FSPE female students $(\mathrm{N}=12)$, the most $(83.33 \%)$ have normal body fat relative values $(\mathrm{BF} \%)$, while only $16.67 \%$ have very high $\mathrm{BF} \%$ values, according to Purenović-Ivanović, T., et al., 2013 [14].

When it comes to visceral fat, however, there is no difference between the two samples of examinees'. The current sample of respondents $(\mathrm{N}=30)$ has an average value of level (4) with an interval (4), while respondents of the younger group ( $\mathrm{N}=12)$, have an average value (3.7) with an interval (3) When we talk about the level of visceral fat, all respondents are in the range (1-9) of normal values (Omron, 2002, 11).

When it comes to relative muscle mass $(\mathrm{M} \%)$, the calculated average is approximately the same in both samples of subjects. The older FSPE female students group $(\mathrm{N}=30)$ has an average score $(29 \%)$ with an interval of $(7.9 \%)$, which makes it more homogeneous than the younger group $(\mathrm{N}=12)$, with an average of $(29.6 \%)$ and the interval (13.1\%), which implies already in the dispersion of individual results.

According to the original table (Omron, 2002, p. 12), the situation regarding the relative skeletal muscle mass ( $\mathrm{M} \%)$ is different in the younger group of FSPE female students $(\mathrm{N}=12)$ : the most $(58.33 \%)$ have normal values of $\mathrm{M} \%$, around $(33.33 \%)$ have high values, and only $(8.33 \%)$ have very high relative muscle mass values $(\mathrm{M} \%)$, according to Purenović-Ivanović, T., et al., 2013 [14].

In determining basal metabolism values, there are no comparable indicators for both samples of examinees'. The calculated average value, in the current sample of FSPE students $(\mathrm{N}=30)$ is $(1150 \mathrm{kCal})$, with an interval of $(377 \mathrm{kCal})$, with the limit values of Min $(1110 \mathrm{kCal})$ and Max $(1487 \mathrm{kCal})$, which indicates a significant lack of inter-group uniformity.

The interpretation and analysis of all measured parameters was based on (Omron Healthcare table), except for Rest/Basal metabolism parameter.

The results obtained show the expected intra-group differences in body characteristics, which are not inherited conditionally, for all of the selected body composition parameters (except BMI). But, although the most of the values are recommended, those low percentages of high body fat $(\mathrm{BF})$, and body mass index (BMI), as well as relative skeletal muscle mass values $(\mathrm{M} \%)$, indicate the heterogeneity of the student population, their sports orientation, and their level of physical activity.

Reasons should be sought in malnutrition or non adequate diet habits (they studied outside the birthplace). Also, the reasons for this situation should be sought in the manner of conducting the entrance exam, and even the insufficiently high criteria for enrolment in the PE studies (except of active 
athletes and former athletes, the enrolment requirements are fulfilled by members of the general population and non-athletes), according to Purenović-Ivanović, T., et al., 2013 [14].

Therefore, it is necessary to find out a more appropriate evaluation system, than the applied credit (point) system, which limits in a great way the ability of the adequate assessment of confirmed candidates, especially those with the limit values, whether in terms of minimum or maximum results. In this manner may be noted justified dissatisfaction with the declared candidates, which are limited by an inadequate rating scale, on a specific part of the entrance exam, without previously proven way of awarding points, favoring the results achieved in previous education, which become basic factors in the formation of rankings for the admission of candidates. Listed by Popovic, R., 2015, [13].

\section{Conclusions}

Testing of the 3rd year study female students at the Faculty of Sports and Physical Education (FSPE), University of Nis, was conducted on 28.06.2016. in the morning hours (up $10: 00 \mathrm{~h}$ to $12: 15 \mathrm{~h}$ ), within of the practical lessons, on the obligatory Curriculum subject Rhythmic gymnastics.

This report presents the results of all female students of the 3rd year of study at the Faculty of Sport and PE, and especially are viewed the results of Aleksandra Popović, as a profile model person presented in form of case study contents, also as co-author of the study.

Age of respondents showed great homogeneity, so, except for one female student, all subjects belong to correspondent age of study year, i.e., appropriate generation regarding the enrolment to the studies of FSPE. The average age of respondents was 23.6 years. The interval between the youngest and the oldest female student is 4.4 years, which is the difference between Min (21.4) and Max (25.8) years of age.

Body Height (BH) of all subjects is measured on-site, using anthropometry by Martin, which was then inputted in the device memory, to determine all other parameters for assessing the body composition. The values of $\mathrm{BH}$ have been reported as precise as $0.5 \mathrm{~cm}$. Average Body High of the female FSPE students was $(164 \mathrm{~cm})$. Range interval value is $(32.5 \mathrm{~cm})$, and this is the difference between Min $(150 \mathrm{~cm})$, and Max $(182.5 \mathrm{~cm})$ score of the measured $\mathrm{BH}$.

Body weight (BW) of FSPE female students, is measured by the digital scale BF511. Values are expressed as precise as $0.5 \mathrm{~kg}$. The average body weight of FSPE female students was $(60 \mathrm{~kg})$, with a determined interval of $(28.5 \mathrm{~kg})$, which is the difference between the Min $(43.7 \mathrm{~kg})$, and Max $(72.5 \mathrm{~kg})$ recorded body weight range values. In addition to the $\mathrm{BW}$, the digital scale presented as well the following parameters for the evaluation of the body composition: body mass index (BMI), the percentage of body fat $(\mathrm{BF} \%)$, the visceral fat $(\mathrm{VF})$, the percentage of skeletal muscles (M\%), and basal metabolism (BM).

Body mass index (BMI) in FSPE female students shows an average value of 21.5 units. It was a determined interval of 8 units, which is the difference between Min (17.7), and Max (25.7) units of this parameter. The average value indicates on normal obesity ( 0$)$, while the range values on Omron scale falls to low obesity (-), and pre-obesity $(+)$.

Body fat percentage (BF\%) indicates an average of $(26.5 \%)$, which fall to 0 (normal) level, and the determined interval between Min (16.5\%), and Max (35.9\%) values of this parameter is $(19.4 \%)$. This indicates the great heterogeneity of the group. Branch values are located in - (low), and + (high) level, and the value of the profile model is $+(33.3 \%)$.

Visceral fat (VF) is located within the normal range in the Omron scale (1-9). The average value is (4) level, the interval is (4), which is the difference between the range values of Min (1) and Max (5), while at the profile model is determined (3) level.

Relative skeletal muscles percentage (M\%) is in the average (29\%). Interval has a value of $(7.9 \%)$, which is the difference between the range of Min (25.8\%), and Max (33.7\%) size of skeletal muscles. The profile model has a rating of (26.8\%). All values are normal according to the OMRON scale, except for the maximum score that falls in the high $(+)$ zone.

Basal metabolism (BM) has an average of $1150 \mathrm{kCal}$, and interval range values between Min $(1110 \mathrm{kCal})$, and Max $(1487 \mathrm{kCal})$ is $(377 \mathrm{kCal})$, while the profile model needs 1367 $\mathrm{kCal}$ for the basal function of the organism at rest/sleep.

\section{References}

[1] Bale, P. (1978). The physiques of physical education students and their relationships to performance. Research Papers in Physical Education, 3 (4), 30-33.

[2] Bale, P. (1979). The relationship between physique and basic motor performance in a group of female physical education students. Research Papers in Physical Education, 1, 26-32.

[3] Bale, P. (1980). The relationship of physique and body composition to strength in a group of physical education students. British Journal of Sports Medicine, 14 (4), 193-198.

[4] Bolonchuk, W. W., Hall, C. B., Lukaski, H. C. \& Siders, W. A. (1989). Relationship between body composition and the components of somatotype. American Journal of Human Biology, 1, 239-248.

[5] Cvetković, M., Obradović, J., Kalajdžić, J. (2008). Effects of Pilates on morphological characteristics of female students of the Faculty of Physical Education. Glasnik Antropološkog društva Srbije, 43, 605-613.

[6] Jachson, A. S., Pollock, M. L. (1985). Practical assessment of body composition. Physician and Sports Medicine, 5, 76-90.

[7] Jović, D., Đurašković, R., Pantelić, S., Čokorilo, N. (2010). Constitutional differences in student from Faculty of Sports and Physical Education. Glasnik Antropološkog društva Srbije, 45, 335-342.

[8] Komiya, S., Masuda, T., Ube, M. \& Mitsuzono, R. (1996). Body size and composition in different somatotypes of Japanese college-aged women. Applied Human Science, 15 (1), $5-11$. 
[9] Krick, C., Raschka, C. (2012). Sports anthropological comparison between male martial arts fighters and the students majoring in physical education. Papers on Anthropology, 21, 155-162.

[10] Krsmanović, B., Jakonić, D., Krsmanović, R., Krsmanović, C. (1997). The somatotype of the Faculty of Physical Culture students. Glasnik Antropološkog društva Jugoslavije, 33 (pp. 177-183).

[11] Ntoumanis, N. (2001). A Step-by-Step Guide to SPSS for Sport and Exercise Studies, edited by Chicago, IL, USA.

[12] Omron (2002). BF511, Body Composition Monitor. Instruction Manual (pp. 16-17).

http://filehost.fonq.nl/Gebruikshandleidingen/Omron/HBF511

[13] Popović, R. (2015). Analysis of the entrance-exam objectivity criteria for the physical education study applicants selection: an overview for the period last up $1970^{\text {th }}$ to $1990^{\text {th }}$. In J. Suchy (Ed.), CZECH KINANTHROPOLOGY, 19 (1), (pp. 46-60). Text book, ISSN 1211-9261.

[14] Purenović-Ivanović, T., Popović, R., Đorđević, M., Živković, D. (2013). Body type and composition of the PE students. In S. Pantelić (Ed.), Book of Proceedings of the XVI Scientific Conference, FIS COMMUNICATIONS 2013“ in physical education, sport and recreation. (pp. 397-404). October, 18-19, 2013, Niš: Faculty of Sport and PE, Serbia. UDC 611.018, ISBN: 978-86-87249-53-0.
[15] Simić, S., Vasić, G., Jakonić, D. (2010). Body height, body mass and nutrition status of students of the University of Novi Sad. Medicina danas, 9 (4-6), 141-146.

[16] Srdić, B., Dmitrić, G. \& Obradović, B. (2009). Anthropological characteristics of students of Faculty of Sports and Physical Education. Glasnik Antropološkog društva Srbije, 44, 463-470.

[17] Weiner, J. S. \& Lourie, J. A. (1969). Human Biology, A guide to Field methods. International Biological Program. Edinburgh: Blackwell Scientific Publications.

[18] World Health Organization (1995). Physical status: the use and interpretation of anthropometry. Report of a WHO Expert Committee. Geneva: WHO.

[19] WMA (2002). World Medical Association Declaration of Helsinki: Ethical principles for medical research involving human subjects.

http://www.fda.gov/ohrms/dockets/dockets/06d0331/06D-033 1-EC20-Attach-1.pdf.

[20] U.S. Department of Health and Human Services (1996). Physical Activity and Health: A Report of the Surgeon General. Atlanta, GA: U.S. Department of Health and Human Services, Centers for Disease Control and Prevention, National Centre for Chronic Disease Prevention and Health Promotion, pp. 83-391. 